\title{
AREMANIA: SUATU BENTUK IDENTITAS PEMERSATU KAUM MUDA KOTA MALANG TAHUN 1992-2000
}

\author{
AREMANIA: A FORM OF UNIFYING IDENTITY \\ AMONG YOUTH IN MALANG BETWEEN 1992-2000
}

\author{
M. Lukman Hakim, Dewi Yuliati, dan Hariono Rinaldi \\ Program Studi Magister Ilmu Sejarah, FIB Universitas Diponegoro \\ Hakeemlukman89@yahoo.com,dewi_yulliati@yahoo.co.id, dan rinardiharyono@yahoo.com
}

\begin{abstract}
This study aims to assess the dynamics of Arema Malang FC. supporters community identity in 1992-2000. In the 1990s, Malang youth troublemakers splited into some gangs in some villages in Malang city. Next, those Malang youth people relized about the need of Malang identity unifier and they chose football to achieve that unity. At the beginning, the behavior of being troublemaker were brought into football scene due to every defeat they got so that they made a fuss. In 1992 the conflict between supporters of Surabaya and Malang occured. This conflict was one of the main factors of the Malang youth unity identity construction. After that incident, the youth/ supporters of Malang chose Aremania as the name, which was the result of Malang supporters agreement to be more orderly and polite. In the end, Aremania, as an identity construction of rioters have become more orderly and polite supporters in 2000.
\end{abstract}

Keywords: identity, aremania, ethos, supporters, gang

Abstrak

Studi ini bertujuan untuk mengkaji dinamika identitas komunitas supoter PS Arema Malang pada tahun 19922000. Pada tahun 1990an kaum muda Kota Malang tukang pembuat onar, meraka terpecah dalam geng-geng antar kampung. Selajutnya kaum muda Kota Malang menyadari akan kebutuhan identitas pemersatu dan mereka memilih sepakbola untuk mewujudkan persatuan tersebut. Pada awalnya perilaku sebagai pembuat onar terbawa ke kancah sepakbola karena setiap kalah mereka membuat keributan. Pada tahun 1992 terjadi konflik antara suporter Surabaya dengan suporter Malang. Konflik dengan suporter Surabaya salah satu faktor utama kontruksi identitas persatuan kaum muda Kota Malang. Setelah peristiwa tersebut suporter Malang menggunakan nama Aremania, nama tersebut merupakan hasil kesepakatan suporter Malang untuk menjadi suporter yang lebih tertib dan santun. Pada akhirnya Aremania merupakan suatu kontruksi identitas dari suporter perusuh menjadi suporter yang tertib dan santun pada tahun 2000.

Kata kunci: identitas, aremania, arek, suporter

\section{Pengantar}

Klub sepakbola telah menjadi ekspresi identitas perlawanan nasional. Warga Catalan yang berasal dari kawasan Barcelona yang sudah lama ingin melepaskan diri dari Spanyol yang kemudian diekspresikan dalam mendirikan tim sepakbola yang bernama F.C. Barcelona sebagai identitas Catalan dan harapan perlawanan terhadap pemeritah pusat. Barcelona boleh kalah dengan tim manapun asal tidak kalah dengan tim asal ibu kota yaitu Real Madrid yang sangat didukung oleh rezim fasis Franco (Wahyudi 2009: 22). Real Madrid digunakan oleh rezim Franco untuk mengangkat citra rezimnya ketika Real Madrid meraih juara Liga Champion, Fernando Maria Castiella Menteri Luar Negeri era Rezim Franco menyebut Real Madrid "duta terbaik yang pernah kami miliki” (Kuper
2010:141). Setiap pertemuan kedua klub yang dijuluki dengan sebutan El Clasico, sampai sekarang menjadi pertemuan yang paling ditunggu penggemar sepakbola.

Sepakbola di Indonesia menjadi olahraga favorit sehingga memunculkan banyak suporter sepakbola seperti Bonek mania (Persebaya), Viking atau Bobotoh (Persib Bandung), The Jack (Persija Jakarta), Pasopati (Persis Solo), Aremania (Arema Indonesia), dan lain-lain. Terbentuknya suporter pertama di Indonesia Bonek mania yang berdiri pada akhir tahun 1988 berawal dari koordinasi Jawa Pos yang dipimpin oleh Dahlan Iskan untuk mendukung Persebaya Surabaya di GBK pada semifinal tahun 1988. Gerakan koordinasi ini menjadi awal era suporter moderen di Indonesia. Dahlan Iskan mengharuskan suporter Surabaya menggunakan 
atribut berwarna hijau sebagai identitas. Istilah Bonek muncul dari celetukan Dahlan Iskan setelah melihat suporter Surabaya yang tidak memiliki tiket. Dahlan Iskan berceletuk "wah, koen iku Bonek rek ". Bonek singkatan dari Bondho Nekat karena ke GBK tidak bawa tiket masuk stadion (Islafatun 2014). Bonek mania memiliki organsasi suporter bernama YSS (Yayasasan Suporter Surabaya). Organisasi ini dibentuk untuk mengkoordinir agar suporter asal Surabaya dapat dikendalikan dan mendapat citra positif di masyarakat.

Rivalitas dalam dunia sepakbola yang timbul tidak luput dari permasalahan sosial dan budaya dalam sebuah masyarakat. Masalah hegemoni dan pengakuan akan 'the one and the best' juga menjadi salah satu permasalahan konflik suporter Indonesia. Persoalan chauvinisme dan fanatisme dalam sebuah masyarakat juga bisa menjadi faktor-faktor pemicu konflik, dan juga soal dendam yang berasal dari peristiwa yang terjadi sebelumnya. Banyak permasalahan yang timbul dalam masyarakat terbawa dalam kancah sepakbola. Rivalitas tersebut terjadi di Jawa Timur yakni antara Surabaya dengan Malang.

Ide pendirian tim sepakbola di Kota Malang berawal dari tawaran seorang Jendral Acub Zaenal kepada anaknya Lucky Acub Zaenal pada tahun 1987. Ide dari sang ayah disambut baik oleh Lucky karena sejalan dengan cita-citanya untuk memperkenalkan Malang kepada masyarakat Indonesia dan bahkan dunia. Sebelumnya, Lucky memiliki sebuah tim otomotif yang berbasis di Malang. Saat Lucky keliling Indonesia untuk melakukan perlombaan, teman-teman kompetitor dari daerah lain selalu menanyakan Kota Malang karena mereka belum mengetahuinya, kecuali kota Surabaya. ${ }^{1}$ Hal ini menjadi salah satu semangat perjuangan untuk mereproduksi identitas baru Arek Malang yang berbeda dengan Arek Surabaya, sekaligus salah satu cara mempromosikan kota di pedalaman Jawa Timur yang bernama Malang. PS Arema resmi berdiri pada 11 Agustus 1987 di Kota Malang dan mengikuti kompetisi Galatama ${ }^{2}$.

\footnotetext{
${ }^{1}$ Wawancara dengan Lucky Acub Zaenal tanggal 22 April 2011.

${ }^{2}$ Galatama merupakan liga yang dianggap profesional pada tahun 1980-1990 an, klub yang berkompetisi di liga tersebut didanai oleh pihak swasta non Anggaran Pendapatan Biaya Daerah (APBD).
}

Suporter adalah elemen penting bagi sebuah klub sepakbola, keberadaannya bisa memberikan manfaat dan kerugian terhadap klub sepakbola yang didukung. Klub sepakbola akan memperoleh pendapatan dari segi ekonomi seperti tiket, penjualan merchandise klub, dan hak siar televisi. Dari aspek sosial, klub juga mendapatkan pengakuan oleh masyarakat terhadap klub sepakbola yang didukung karena klub tersebut mewakili daerah mereka. Banyak cara untuk mendapatkan pengakuan masyarakat mulai dari pembentukan dan perkumpulan suporter hingga mendatangkan pemain bintang. Masyarakat Malang mendukung PS Arema karena berbagai hal, kebutuhan pengakuan dari daerah lain, kekecewaan dari pengurus Persema Malang, rivalitas dengan suporter klub lain, dan prestasi PS Arema. Konstruksi identitas komunitas Aremania dapat dilihat ketika PS Arema mengikuti beberapa liga yakni Galatama, Liga Indonesia, dan Liga Super Indonesia.

Penanganan suporter sepakbola di Indonesia sangat rumit dibandingkan dengan negara-negara Eropa yang sudah lebih profesional dalam pengelolaan sumber daya manusianya. Aremania, suporter dari Arema Indonesia yang berkembang menjadi selayaknya penonton bola yang ramai sorak-sorai dan penuh kreatifitas, tidak luput dari bentrokan dengan suporter lain. Sangat menarik jika melihat dinamika pembentukan identitas Arek Malang tahun 1992 hingga tahun 2000. Aremania sendiri tidak bisa dipisahkan dari PS Arema Malang sebagai klub sepakbola yang berasal dari Malang, sehingga keberadaan komunitas ini sangat identik dengan klub yang didukungnya. Kehidupan sosial masyarakat Malang tidak dapat dipisahkan dari klub sepakbola PS Arema Malang, karena pertanda-pertanda/Identitas yang digunakan Aremania juga digunakan dalam kehidupan sosiokultural-ekonomi masyarakat Malang dalam kehidupan sehari-hari.

\section{Metode Penelitian}

Penelitian ini merupakan kajian sejarah sosial yang dituangkan secara deskriptif-naratifanalisis dengan mengunakan pendekatan sejarah sosial budaya. Ada empat tahapan dalam metode penelitian sejarah, yaitu, heuristik, kritik, interpretasi dan hitrografi. Pertama, heuristik adalah mencari jejak-jejak peristiwa (trace) atau lebih dikenal dengan pengumpulan data. Sumber menurut bahannya ada dua yaitu tertulis dan tidak tertulis, sumber dibedakan menjadi dua 
yaitu: (a) sumber primer seperti sumber lisan dari pelaku sejarah, surat kabar, dan dokumentasi yang sezaman dengan peristiwa sejarah, (b) sumber sekunder adalah sumber yang diambil dari buku, atau observasi dari para ahli sejarah. Kedua, kritik sumber yakni pengujian mengenai kebenaran dari sumber, sehingga dengan demikian karya sejarah yang dihasilkan merupakan produk dari proses (Kuntowijoyo 2001). Ketiga, interpretasi yaitu peneliti melakukan penafsiran terhadap faktafakta yang telah diperoleh melalui kritik sumber dengan cara mencari dan menyusun hubungan antar fakta-fakta yang relevan, kemudian disusun secara kronologis dalam hubungan sebab-akibat yang dianalisis menggunakan konsep-konsep Ilmu Sejarah dan Ilmu Sosial. Keempat, penulisan sejarah atau historiografi merupakan tahap akhir dari keseluruhan proses penelitian peristiwa sejarah. Penulisan sejarah aspek kronologi menjadi sangat penting untuk membedakan penelitian sejarah tersebut dengan penelitian yang lain.

\section{Kerangka Konseptual}

Penelitian tentang sejarah Aremania mengunakan konsep dinamika yaitu tenaga atau kekuatan penggerak perubahan. Dalam hal ini, dinamika mencakup interaksi dan interdependensi antara anggota kelompok dengan kelompok secara keseluruhan. Keadaan ini dapat terjadi karena selama ada kelompok, semangat kelompok terus-menerus ada dalam kelompok itu. Oleh karena itu kelompok tersebut bersifat dinamis, artinya karakter kelompok yang bersangkutan dapat berubah jika ada kekuatan penggeraknya. Penelitian ini mengunakan konsep dinamika untuk melihat maju mundurnya gerakan suporter asal Malang dalam mendukung PS Arema Malang. Pada awal tahun 1990-an Suporter asal Jawa Timur dianggap perusuh, kemudian pada tahun 1994 hingga awal tahun 2000 mengkontruksi sebagai suporter tertib dan kreatif.

Konsep selanjutnya adalah identitas sosial, yaitu bagian dari konsep diri individu yang bersumber dari pengetahuan mereka tentang keanggotaan dalam suatu kelompok sosial dengan berbagai jenis nilai, norma, dan ikatan emosional yang berkembang dalam kelompok tersebut. Identitas tersebut merupakan identitas kolektif yang tidak mensyaratkan masing-masing anggota kelompok sosial tersebut untuk saling mengenal dan memiliki hubungan personal yang dekat. Identitas memang diperlukan sebagai pembeda antara aku dan dia, aku dan mereka. Mengidentifikasi suatu identitas tidak selalu mudah, terkadang orang pun ragu untuk memilih kelompok ini atau itu. Hasil dari identifikasi tidak jarang menimbulkan konflik antar kelompok, bahkan pengaruh terbesar dari identifikasi identitas sosial adalah menciptakan jarak antara in-group dan out-group (Soekanto 1987:110). Dapat disimpulkan bahwa identitas sosial adalah bagian dari konsep diri individu yang berasal dari pengetahuannya selama berada dalam kelompok sosial tertentu dengan disertai internalisasi nilai-nilai, emosi, partisipasi, rasa peduli dan bangga sebagai anggota kelompok tersebut.

Tiap individu dilahirkan dalam suatu struktur sosial yang objektif, tempat ia menjumpai orang-orang yang berpengaruh dan bertugas mensosialisasikannya. Orang-orang di sekitar individu berpengaruh sebagai penghubung dunia dengan dirinya dan memodifikasi dunia itu selama proses perantaraan berlangsung. Individu memilih aspek-aspek dari dunia itu yang sesuai dengan lokasi individu sendiri dalam struktur sosial dan dasar watak-watak khas individual yang berakar dalam biografinya. Melalui identifikasi dengan orang-orang yang berpengaruh itu individu menjadi mampu untuk mengidentifikasi dirinya sendiri, untuk memperoleh suatu identitas yang secara subjektif koheren dan masuk akal. Individu "mengidentifikasikan diri" dengan orang-orang yang berpengaruh, merupakan semacam bagian-bagian dalam kehidupan individu dari dialektika umum masyarakat (Berger \& Luckmann, 1990: 189190).

Seseorang atau kelompok dapat mengkontruksi identitas sesuai dengan kebutuhannya, ada dua bentuk pembangunan Identitas (Castells 2010: 08), yaitu:

(a) Identitas Legitimasi (Legitimizing Identity), yaitu identitas yang diperkenalkan oleh sebuah institusi yang mendominasi suatu masyarakat untuk merasionalisasikan dan melanjutkan dominasinya terhadap aktoraktor sosial, seperti suatu institusi negara yang mencoba meningkatkan identitas kebangsaan anggota masyarakat.

(b) Identitas Resisten (Resistance Identity), yaitu identitas yang dibentuk oleh aktor-aktor yang dalam kondisi tertekan oleh dominasi pihak-pihak lain, sehingga mereka membentuk 
resistensi dan pemunculan identitas yang berbeda dari pihak yang mendominasi, dengan tujuan untuk keberlangsungan hidup kelompok atau golongannya.

Komunitas Aremania termasuk dalam kedua bentuk identitas tersebut di atas, karena kemunculannya berasal dari keinginan komunitas untuk eksis dalam dominasi dan persaingan kelompok lain. Komunitas Aremania terbentuk dari identitas resisten yang mana suporter dari Malang selalu disamakan dengan suporter dari Surabaya, dalam hal ini Bonek yang mendominasi Jawa Timur pada era 1990-an. Pada era tersebut suporter yang berasal dari Jawa Timur mempunyai stereotip negatif.

\section{Pembahasan}

Nama Arema sebenarnya sudah ada sejak zaman Singhasari, seperti yang disebutkan dalam Negarakretagama bahwa Kebo Arema sebagai patih yang dipercaya oleh Raja Singhasari. Nama Arema juga disebutkan dalam Piagam Penampihan, yang dikeluarkan pada bulan Kartika tahun 1191 Saka (OktoberNopember 1269). Pada piagam tersebut tercatat bahwa Patih Kebo Arema dan Sang Ramapati, yang sangat dipuja sebagai penasehat sang prabu dalam mengadakan hubungan dengan pembesarpembesar di Madura dan Nusantara (Mulyana 1979). Antara Kebo Arema dan PS Arema sebagai klub sepakbola memang tidak ada kaitan yang mendasar karena jarak yang begitu jauh yaitu kurang lebih sekitar 7 abad. Nama PS Arema sendiri diambil dari singkatan Persatuan Sepakbola $\mathrm{Arek}^{3}$-Malang yang berdiri pada tahun 1987 di kota Malang.

Pada tahun 1970-an sampai tahun 1980an perekonomian di kota Malang sudah mulai mengarah pada pengembangan industrialisasi seperti pabrik rokok Bentoel, perakitan karoseri mobil Adi Putro, industri keramik Dinoyo Kota Malang dan sebagainya. Melalui industrialisasi inilah perubahan sosial mulai terasa di kota Malang. Secara bertahap masyarakat kota mulai meninggalkan kegiatan yang berorientasi pada

${ }^{3}$ Arek adalah sebutan untuk pemuda di Jawa Timur, kebudayaan Arek yang wilayah persebarannya di Surabaya dan Malang yang merupakan pertemuan antara budaya Mataraman (Jawa Timur bagian barat), Madura (Jawa Timur bagian utara) dan Pandalungan (Jawa Timur bagian timur). Budaya arek dikenal dengan semangat juang yang tinggi, terbuka terhadap perubahan dan mudah beradaptasi. bidang agraris. Masyarakat kota Malang mulai mengalami keberagaman dalam berbagai hal, termasuk mengenai budaya. Hal tersebut tergambar pada generasi muda kota Malang pada tahun 1980-1990an yang terpecah menjadi genggeng antar gang/kampung kota Malang. Pada medio tersebut pemuda kota Malang sudah mengikuti tren kota-kota lain di Indonesia, yakni budaya populer yang berkembang secara masif (Yovi Ardivitiyanto2014: 97). Arek Malang pada tahun 1980-1990-an masih terpecah dalam genggeng antar kampung, anggotnya mayoritas kaum muda Malang. Nama geng tersebut diambil berasal dari nama gang atau kampung seperti, geng Aregrek berasal dari sekitar Jl. Basuki Rachmat, Arnak (Armada Nakal) Sukun, Anker (Anak Keras) Jodipan, Argom (Armada Gombal) Kidul Dalem, Arpanja (Arek Panjaitan), Betek Fanhalen (Federasi Anak Nakal Halangan), Claket SAS (Sarang Anak), Geng Inggris Kasin Jrot Ermera, Saga (Sumbersari Anak Ganas), Warrior (Klayatan), dan Zhegal (Zhetan Galunggung). Akibatnya pemuda Malang saat itu memiliki identitas atau stereotip sebagai tukang pembuat onar ketika di dalam maupun keluar daerah Malang. Terpecahnya pemuda Malang dalam geng-geng antar kampung sehingga membutuhkan identitas permersatu.

Identitas budaya masyarakat berkembang dinamis mengikuti zaman sehingga menciptakan simbol budaya yang digunakan, serta makna yang diberikan pada simbol dan gagasan yang dianggap layak atau tidak layak (Iskandar 2004). Masyarakat Kota Malang menganggap bahwa budaya populer merupakan identitas budaya mereka sehingga pada awal perkembangan dianggap layak, akan tetapi pada titik puncak perkembangan tersebut muncul efek negatif yang menyebabkan hilangnya persatuan dan kesatuan kaum muda kota Malang. Sehingga kaum muda Malang membutuhkan satu identitas yang mempersatukan semua lapisan masyarakat kota.

Tahun 1987 tanggal 11 Agustus Persatuan Sepakbola (PS) Arema Malang didirikan di Malang untuk berkompetisi di Galatama. Bersamaan dengan berdirinya klub maka didirikan wadah suporter yang bernama Arema Fans Club (selanjutnya AFC). Wadah ini berusaha menggali dukungan dari kaum muda Malang yang terpecah-pecah dalam geng antar kampung Kota Malang. AFC menggunakan propaganda bahwa siapapun yang mewaliki atas nama Kota Malang harus didukung termasuk 
Persema Malang klub perserikatan ${ }^{4}$ asal Malang. Momentum AFC mempersatukan kaum muda Malang ketika pada tahun 1992 Persema memiliki prestasi yang cukup baik karena bisa bersaing dengan Persebaya Surabaya. Kaum muda Malang menganggap bahwa Surabaya representasi pusat yang selalu dianggap terbaik, sedangkan Malang sebagai kota pedalaman yang tidak akan pernah bisa bersaing dengan Surabaya.

\section{Konflik antara AFC dengan Suporter Sepak Bola Surabaya Tahun 1992}

Sejak musim kompetisi 1991-1992 Persema Malang promosi ke devisi utama. Perserikatan bergabung di wilayah timur bersama Persebaya Surabaya, Persegres Gresik, PSM Makassar, Persiba Balikpapan dan PSIS Semarang. Selama musim tersebut, Persema Malang menjadi tim kejutan karena dapat melanjutkan ke putaran kedua. Pada putaran kedua dan kompetisi menyisakan tiga pertandingan, Persema Malang mempunyai peluang yang sama dengan Persebaya Surabaya, PSM Makassar, dan Persegres Gresik untuk lolos ke babak 6 besar di Senayan. Kondisi ini kemudian menjadi awal yang menyebabkan semakin memanasnya antar suporter tim terutama rivalitas antara suporter Persema Malang dan Persegres Gresik. Hal ini didukung oleh pernyataan Endar pendiri AFC (Arema Fans $C l u b$ ) sebagai berikut:

\begin{abstract}
"Waktu itu suporter Malang yang mendukung Persema dan Arema adalah AFC. Waktu itu kebetulan kompetisi perserikatan yang mempertemukan antara Persema dengan Persebaya kan keos (ricuh) di stadion Gajayana, kebetulan pertandingan terakhir Persema menuju 6 besar". 5
\end{abstract}

Pada bulan Februari tahun 1992 terjadi 2 tragedi kerusuhan besar yang melibatkan kedua suporter. Pertama, tragedi Gajayana pada tanggal 4 Februari 1992. Peristiwa tersebut bermula pada saat Persema Malang menghadapi Persebaya Surabaya di Stadion Gajayana Malang. Kerusuhan berawal di tengah lapangan ketika terjadi peristiwa pemukulan yang dilakukan oleh

${ }^{4}$ Perserikatan adalah Liga Amatir yang bergulir sejak 1930-1994, persertanya berasal dari klub yang dibina dan didanai oleh pemerintah daerah.

${ }^{5}$ Wawancara dengan Hendar tanggal 27 September 2011 di Kota Malang pemain Persema Malang terhadap pemain Persebaya Surabaya. Hal tersebut mengakibatkan kericuhan di dalam stadion dan melibatkan para suporter yang melakukan pelemparan ke dalam lapangan. Pertandingan tersebut dimenangkan Persema Malang, skor akhir 1 : 0 untuk kemenangan Persema Malang. Setelah pertandingan tersebut, Walikota Malang Soesamto sekaligus sebagai ketua umum Persema Malang meminta maaf secara tertulis pada tanggal 5 Februari kepada Persebaya Surabaya. Soesamto melakukan klarifikasi bahwa kejadian pemukulan sebelum pertandingan Persema Malang vs Persebaya Surabaya terjadi secara tiba-tiba tanpa direncanakan sebelumnya (Suara Karya. 8 Februari 1992).

Betulkah suporter Malang suka menimbulkan kerusuhan? Kalimat tanya tersebut ada dalam surat kabar Jawa Pos di salah satu kolom berita yang berjudul "Manis, Asal tidak Digarahi". Kalimat itu muncul setelah kerusuhan di Stadion Gajayana Malang. Pada kolom berita menyebutkan bahwa sebenarnya koordinator suporter Persema secara pelan-pelan membenahi suporter dalam koordinasi maupun dalam mendukung tim kesayangannya. Permasalahannya tidak semua suporter tergabung dalam keanggotaan. Suporter yang tidak masuk dalam keanggotaan biasanya anak-anak kecil yang disebut "Pasukan Bodrex". Pasukan ini nekad dalam melakukan aksinya, sebelum peristiwa stadion Gajayana terjadi pasukan ini melakukan penyerangan terhadap pemain Mitra Surabaya ketika uji coba melawan Persema Malang (Jawa Pos: 12 Februari 1992). Alasannya penyerangan karena media massa terlalu membesar-besarkan Mitra Surabaya dan Persebaya. Peristiwa kerusuhan yang terjadi di stadion Gajayana Malang memang menjadi berita hangat karena suporter di Malang mulai menemukan gairah dalam mendukung klub sepakbola yang berasal dari Malang melawan tim dari ibukota propinsi Jawa Timur Mitra dan Persebaya Surabaya.

Peristiwa kedua pada bulan yang sama yakni tragedi Gresik terjadi pada tanggal 14 Februari 1992 di stadion Petrokimia Gresik. Persegres Gresik dan Persema Malang memiliki peluang yang sama untuk lolos ke Senayan dalam babak 6 besar. Hal ini menjadikan pertandingan tersebut penting bagi kedua tim. Secara resmi pengurus Persema Malang tidak mengirimkan suporter ke Gresik, namun suporter Persema berjumlah 500 orang tetap berangkat ke Gresik yang didanai oleh Pemkot Malang 
sebesar 3,5 juta melalui koordinator suporter mereka. Keberangkatan suporter menimbulkan rasa khawatir pengurus Persema Malang akan terjadinya bentrokan balasan dari suporter Surabaya sebagai kelanjutan tragedi Gajayana sebelumnya. Pada akhirnya suporter Persema Malang yang berjumlah kurang lebih 500 orang tetap berangkat ke Gresik meskipun tidak secara resmi karena didasari niat untuk mengawal tim Persema Malang atas tragedi Gajayana. Hal ini didukung oleh pernyataan Endar sebagai koordinator AFC (Arema Fans Club) sebagai berikut:

Kita sudah mengetahui bahwa berangkat ke Gresik untuk perang, karena suporter Surabaya sudah menunggu untuk perang ketika kita berangkat ke Gresik. Sedangkan kita tidak tahu kondisi yang di Malang, ternyata yang di Malang banyak orang ingin berangkat. Akhirnya mereka demo hari itu juga waktu Persema Malang main di Gresik, mereka menuntut ke Wali Kota Malang agar diberangkatkan ke Gresik. ${ }^{6}$

Pada hari pelaksanaan, pertandingan tersebut ditunda hingga 2 jam karena adanya pelemparan batu oleh penonton di tribun timur terhadap pemain Persema Malang. Pertandingan dimulai pada pukul 15.25 WIB dan baru berjalan 10 menit terjadi keributan di tribun timur berasal dari suporter Surabaya dalam jumlah yang cukup besar melempari pemain Persema Malang dengan batu, botol-botol serta benda keras lainnya. Kejadian ini memaksa wasit Eddy Wijaya asal Garut menghentikan pertandingan hingga 2 jam. Pertandingan baru dilanjukan kembali setelah kerusuhan dapat diatasi oleh Polri/ABRI yang berjumlah 1500 personil (Merdeka, 15 februari 1992). Pada akhirnya, pertandingan terlaksana dengan kemenangan Persatuan Sepakbola Gresik (Persegres) dengan skor 1 : 0. Satu gol kemenangan Persegres dicetak oleh Zaenal Arifin. Pertandingan ini diwarnai oleh kartu merah pemain Persema Malang Syarifudin Zuhri, karena permainannya kasar dan membahayakan lawan. Hasil pertandingan ini membuat Persema Malang gagal ke babak 6 besar yang berlangsung di Senayan Jakarta.

Suporter asal Malang pada tahun 19921993 masih identik dengan perilaku kekerasan, karena masih kuatnya pengaruh geng-geng antar

${ }^{6}$ Wawancara dengan Hendar tanggal 27 September 2011 jam 19.16 WIB. kampung. Alasan suporter Malang berperilaku kasar terhadap lawan yang datang ke Malang tujuannya adalah untuk memperkenalkan diri mereka bahwa Arek Malang memiliki identitas yang berbeda dengan yang lain terutama dengan Surabaya. Ketika melawan tim yang berasal dari Surabaya, mereka selalu ingin menang dengan cara apapun meskipun cara tersebut dengan teror kekerasan fisik maupun mental. Oleh sebab itu konsep identitas in group-out group berlaku pada suporter Malang dan Suporter Surabaya setelah peristiwa di bulan Februari 1992. Hal ini mememculkan identitas yang berbeda antara Arek Surabaya sebagai perwakilan pusat ibukota propinsi Jawa Timur sedangkan Arek Malang representasi daerah pedalaman Jawa Timur.

\section{Suporter Malang di Liga Indonesia (Tahun 1994-1997)}

Pada tahun 1994 menjadi tahun terakhir PS Arema Malang berkompetisi di Galatama sebelum mengikuti kompetisi baru bernama Liga Indonesia. Prestasi PS Arema menurun setelah juara Galatama pada tahun sebelumnya, bahkan bertanding di kadang sendiri tiga kali seri dan klimaksnya kalah dari satu rival dari tim sesama Jawa timur yakni Petrokimia Gresik. Kekalahan tersebut mengakibatkan pembakaran bendera Arema sebagai bentuk protes terhadap tim yang dipuja dan didukung. Pada tahun ini PS Arema Malang terancam bubar di tengah jalan akibat kekurangan dana untuk berlaga di Galatama (Merdeka 17 Mei 1994). PS Arema Malang terselamatkan dari kebangkrutan karena usaha pengurus dan fans Arema yang sudah dikenal oleh pengemar bola Indonesia. Sehingga pengurus melihat potensi besar ada di fans Arema yang mulai berkembang setelah PS Arema Juara Galatama 1993.

Semenjak itu muncul etos ${ }^{7}$ Bondho Dhuwek. Bondho Duwek tiket dianggap menolong keberlangsung PS Arema sebagai kebanggaan masyarakat Malang sehingga muncul etos/pandangan bahwa menjadi suporter

${ }^{7}$ Etos adalah pandangan hidup manusia untuk menghayati hidup yang ditandai dengan kerja keras untuk memperoleh sesuatu. Seperti dalam masyarakat agraris yang sistem produksinya memakai tenaga manusia secara intensif akan menimbulkan gaya kerja bercorak kolektif dan komunal, maka terbangunlah gaya kerja dalam sifat gotong-royong yang kuat untuk memperoleh hasil yang maksimal (Sartono 1993:103-106). 
PS Arema harus Bondho Duwek (bekal uang). Menjadi suporter PS Arema harus sadar bahwa klub kesayangannya tidak sekaya klub lain yang sumber dananya dari APBD, masuk stadion harus bayar dan harus malu jika masuk stadion secara gratis. Ada semacam anjuran jika seorang suporter PS Arema tidak Bondho Duwek lebih baik tidak berangkat ke stadion atau bisa mendengarkan lewat siaran radio/lewat televisi, karena jika memaksa akan terjadi potensi kerusuhan yang pada akhir merugikan PS Arema itu sendiri. Etos Bondho Duwek juga semacam cara bagi suporter PS Arema untuk membedakan mereka dengan pendukung Persebaya yakni Bonek/ Bondho Nekad (Mohamad 2016: 21).

Liga Indonesia I adalah liga sepakbola hasil dari pengabungan Galatama dan Liga perserikatan. Galatama pada saat itu memang diikuti oleh tim-tim yang sepenuhnya didanai oleh pihak swasta sehingga dianggap sebagai liga profesional pada saat itu, akan tetapi Galatama mengalami kemunduran pada tahun 1994. Sebenarnya banyak suporter yang datang ke stadion menonton langsung Galatama, namun pelan-pelan kehilangan kepercayaan masyarakat karena klub Galatama disinyalir terlibat dalam permainan skor. Sehingga klub Galatama dengan mudah melakukan permainan skor untuk menghidupi tim. Sedangkan liga Perserikatan dianggap sebagai liga Amatir karena pendanaan berasal dari APBD sehingga pada saat itu perlunya penyatuan dua liga ini. Tujuan utama dibentuknya Liga Indonesia untuk menyelamatkan kompetisi nasional. Maka kompetisi sepakbola untuk pertama kalinya membentuk satu kompetisi penuh. Liga Indonesia I diikuti oleh 34 tim dibagi menjadi 2 wilayah Timur dan wilayah Barat. Penyatuan ini mempunyai dampak yang cukup besar, dari segi pengawasan kompetisi menjadi satu pintu dan pengawasan lebih mudah. Dari sisi lain ada permasalahan ekonomi untuk klub-klub peserta yang bukan berasal dari Perserikatan, klub yang berasal dari Galatama yang pendanaannya berasal dari swasta hanya bertahan beberapa musim saja.

Liga Indonesia II 1995-1996 klub yang berasal Galatama yang masih bertahan seperti Pelita Jaya, Bandung Raya, Semen Padang, Mitra Surabaya, Pupuk Kaltim Bontang (PKT), Gelora Dewata, Asyaabaab Grup Salim (ASGS), Arseto Solo, Mataram Indocement dan PS Arema Malang, klub yang bertahan ini bisa bertahan karena sumber dana berasal perusahan besar atau basis pendukung yang besar. PS
Arema Malang salah satu klub yang tidak mempunyai dana besar dan hanya mengandalkan basis penonton yang hadir ke stadion.

Liga Indonesia III 1996-1997 menjadi kompetisi yang menarik bagi masyarakat Jawa Timur terutama Surabaya dan Malang. Kedua tim mempunyai basis suporter besar, Bonek mendukung Persebaya sedangkan Aremania ${ }^{8}$ muncul mendukung PS Arema. Aremania berasal dari kata Arema dan Mania yang berarti seseorang yang gemar, cinta pada Arema. Penyebutan nama Aremania secara kolektif di kalangan pendukung PS dimulai pada tahun 1997 (Jawa Pos. 11 Agustus 2001). Nama Aremania yang mudah didengar dan diingat oleh masyarakat membuat Aremania terus berkembang. Persaingan yang awalnya berlangsung di lapangan sepakbola berlanjut ke luar lapangan sepakbola terutama untuk pendukung kedua tim. Putaran pertama saja persaingan kedua belah pihak sudah memanas, hal ini dikarenakan ke dua tim saling bergantian memimpin puncak klasemen sementara putaran I. Pada pertandingan putaran pertama PS Arema menjadi tuan rumah di Malang tepatnya di stadion Gajayana. Pertandingan ini dilaksanakan pada tanggal 19 Februari 1997, adu gengsi kedua kota tidak terhindarkan antar pendukung masing-masing klub.

Sebelum pertandingan dimulai oknum Bonek asal Surabaya pukul 14.00 WIB sudah membuat kerusuhan di Lawang Kabupaten Malang ketika petugas keamanan menghentikan

${ }^{8}$ Nama Aremania mulai muncul pada Liga Indonesia I tahun 1994, komunitas suporter Aremania muncul tanpa pemimpin dan tidak ada aturan secara resmi layaknya sebuah organisasi. Aremania bisa disebut dengan kumpulan orang yang mempunyai hobi sama yang mendukung PS Arema. Waktu atau tanggal lahir berdirinya Aremania secara resmi belum ditentukan, oleh sebab itu Aremania tidak pernah berulang tahun. Menurut Ovan Tobing ${ }^{8}$ nama Aremania berawal dari simbol yang terdapat di jaketnya.

"Saya memakai jaket berwarna merah karena ini dibuat oleh Djarum, dan nama Aremania tercantum pada jaket tersebut, namun itu tidak masalah yang penting nama Aremania sekarang muncul dan mendunia". (Wawancara dengan Ovan tobin)

Meskipun sudah adanama Aremania hanya digunakan untuk komunitas kecil di kalangan suporter PS Arema, hal tersebut karena sebagian besar suporter PS Arema masih mencari identitas baru setelah AFC bubar. 
truk yang di tumpangi Bonek. Sekitar 50 suporter mengambil jalan pintas dengan cara menghentikan kereta dari Surabaya ke Malang dengan cara melempari kereta mengunakan batu. Sementara di stadion Gajayana situasi relatif tenang akan tetapi bagi kub Persebaya mekhawatirkan karena penonton meluber mendekati bangku cadangan tim Persebaya. Pada menit 24 Persebaya unggul berkat gol dari Jacksen F Tiago, gol itu memancing suporter Arema meneriakan "muleh tawur". Beberapa menit kemudian gol Arema menyamakan kedudukan 1-1 membuat suasana menjadi tenang. Usai pertandingan rombongan Persebaya tidak masuk ke kamar ganti pemain, seperti biasa setelah bertanding akan tetapi Persebaya langsung masuk kendaraan tentara. Tim Persebaya tidak kembali ke hotel Kartika Kusuma tetapi langsung ke markas Kostrad di Singosari setelah itu melanjutkan perjalanan pulang ke Surabaya (Jawa Pos, 20 Februari 1997).

Sisi lain dari pertandigan PS Arema Malang vs Persebaya Surabaya adalah membludaknya penonton. Sekitar 30 ribu penonton datang ke stadion Gajayana Malang, ternyata jumlah tiket yang disediakan 16 ribu tidak semuanya terjual. Hal ini dikarenakan, Pertama, banyaknya calo, Kedua, sebelum pintu dibuka sudah ada pintu yang jebol yang mengakibatkan membludaknya penonton. Ketua panitia Eko Subekti mengatakan "Meskipun jebol yang mengkibatkan penonton tanpa tiket bisa masuk, pendapatan dari tiket yang sudah terjual bisa menyambung kehidupan PS Arema". Setelah Persema Malang mengalami penurunan prestasi, PS Arema bisa mewakili Gregetarekarek Malang dalam percaturan sepakbola Indonesia. PS Arema memiliki modal semangat tanding dan suporter yang gila bola. Dalam pertandingan tersebut suporter Arema cukup kreatif dengan cara menerbangkan potonganpotongan kertas, memoles wajah dengan cat warna-warni. Sedangkan bendera-bendera yang dua musim kompetisi liga dipasang sekeliling lapangan Gajayana mulai berkurang. Suporter Malang pada pertandingan ini lebih mengadalkan pada teriakan, tepuk tangan dan koor Arema sepanjang pertandingan (Jawa Pos 21 februari 1997). Pada akhir kompetisi PS Arema Malang lolos 12 besar di Ujungpandang/Makasar dan tidak lolos semifinal yang di langsung di Senayan.
Sejarah Komunitas Aremania Tahun 19972000

Sejak Aremania menjadi nama suporter PS Arema pada tahun 1997 memang tidak mempunyai organisasi secara resmi (formal). Komunitas Aremania bisa dikatakan informal group yang mana tidak mempunyai struktur dan organisasi tertentu atau pasti (Basrowi, 2005: 56). ${ }^{9}$ Hal itu dibuktikan dengan tidak adanya organisasi inti dan ketua secara resmi atas nama Aremania. Hal tersebut sesuai dengan budaya Arek yang mempunyai sifat egaliter. (Ayu Surtarto, 2004: 4). Aremania ketika berada di stadion maka menjadi Crowd atau kerumunan karena di dalam stadion mereka tidak memakai nama korwil tapi Aremania seutuhnya. Ketika ada suatu kericuhan maka nama Aremania yang menjadi sorotan utama bukan korwil. Maka disini pentingnya solidaritas kelompok untuk saling menjaga tingkah laku agar tidak berlebihan menjurus ke anarkis (Andreas 2009:19-33). ${ }^{10}$

Penggunaaan nama ini untuk mengidentifikasi kelompok pendukung PS Arema dengan kelompok lain.Penggunaan nama Aremania menjadikan rekontruksi identitas baru suporter PS Arema yang sebelumnya dikenal

${ }^{9}$ Informal group adalah kelompokkelompok yang tidak mempunyai struktur dan organisasi tertentu atau pasti. Kelompok-kelompok tersebut biasanya terbentuk karena pertemuan yang berulang kali dan itu menjadi dasar bagi bertemunya kepentingan-kepentingan bersama.

${ }^{10}$ Aremania memiliki suatu mekanisme nilainilai yang telah menginternalisasi dalam diri anggotanya. Nilai-nilai tersebut adalah untuk menjaga nama baik kota Malang, Arema dan Aremania. Nilainilai tersebut tidak hanya bagaimana bentuk dukungan Aremania terhadap tim Arema, tetapi juga turut mempengaruhi perilaku anggota Aremania dalam kegiatan-kegiatan lain. Misalnya penggunaan bahasa walikan yang sangat umum di kalangan Aremania, termasuk dalam kegiatan sehari-hari. Termasuk juga nilai-nilai mengenai penyimpangan atau tindakan kejahatan. Salah satu bentuk penyimpangan yang sering dilakukan Aremania dan suporter lain adalah mabuk minuman keras saat mereka menonton pertandingan.Nilai-nilai tersebut turut pula mengatur perilaku anggota Aremania sehingga memiliki kepatuhan terhadap norma-norma tersebut. Sehingga menciptakan kontrol sosial diantara mereka. Nilai-nilai inilah yang akan menentukan peran kontrol sosial internal yang informal pada Aremania dalam mencegah terjadinya kerusuhan suporter. 
keras, gemar melakukan kericuhan menjadi suporter yang lebih kreatif dan santun. Identitas legitimasi (legitimizing identity), yaitu identitas yang diperkenalkan oleh sebuah institusi yang mendominasi suatu masyarakat untuk merasionalisasikan dan melanjutkan dominasinya terhadap aktor-aktor sosial, seperti suatu institusi negara yang mencoba meningkatkan identitas kebangsaan anggota masyarakat. Adanya aktoraktor penggerak seperti Lucky Acub Zainal salah satu pendiri PS Arema. Ovan Tobing Orang pertama yang mengenalkan nama Aremania lewat jaket yang ia gunakan ketika menjadi MC pertandingan kandang PS Arema di Stadion Gajayana. Yuli Sumpil dan El Kepet dua dirigen Aremania yang bertindak sebagai pemimpin ketika di stadion untuk bernyanyi dan memimpin koreografi Aremania.

Identitas resisten (resistance identity), yaitu identitas yang dibentuk oleh aktor-aktor yang dalam kondisi tertekan oleh dominasi pihak-pihak lain, sehingga mereka membentuk resistensi dan pemunculan identitas yang berbeda dari pihak yang mendominasi, dengan tujuan untuk keberlangsungan hidup kelompok atau golongannya. Aremania yang berasal dari Malang tidak ingin disamakan dengan Bonek yang bersal dari Surabaya meskipun sama-sama berasal dari Jawa Timur. Bonek (Bondho Nekad) identik dengan modal keberanian tanpa mengenal takut, sedangkan Aremania membentuk etos bondho duwek yang mempunyai arti bermodal uang. Etos ini menjadi salah satu keberhasilan PS Arema bertahan di Liga Indonesia dalam krisis keuangan karena Aremania mempunyai kesadaran bahwa klub yang didukungnya adalah klub swasta tanpa dana APBD.

Liga Indonesia IV 1997-1998 menjadi tahun terakhir suporter Arema bisa datang dan mendukung langsung PS Arema bermain di kandang Persebaya Gelora 10 November pada tanggal 17 November 1997. Aremania bisa berangkat karena ada jaminan dari Kolonel Sutrisno yang menjabat sebagai Dandim, pada pertemuan di Klub Bunga Batu Kolonel Sutrisno menjanjikan akan memberangkatkan Aremania ke Surabaya. Menjelang beberapa hari sebelum pertandingan Aremania menagih janji kolonel. Setelah mendapat jaminan keamanan, sehari sebelum pemberangkatan diumumkan di depan stasiun Kota Malang ditulis di kardus
"Pendaftaran Tour Surabaya". ${ }^{11}$ Setelah pendaftaran ditutup yang mengikuti tour Surabaya 182 Aremania berangkat dari Stasiun Kota Malang yang terdiri seksi keamanan Aremania Cak Kaji Dengkling dan Saiful Gluduk (bagian menjaga gerbong kereta api) sebelum berangkat koordinator Endik (Korwil Gadang). Ada seorang wanita bernama Desy Metal adalah wanita pertama dan satu-satunya yang ikut tour "Budal Mati", Desy metal bisa dikatakan cikal bakal Aremanita. ${ }^{12}$ Pada saat berangkat menuju Surabaya gerbong ditutup, menghindari ada yang masuk dan ikut diluar daftar peserta resmi, tetapi ketika di stasiun Singosari ada 2 Aremania yang memaksa ingin ikut dan membayar, akhirnya jumlah total perserta tour Surabaya ada 187 Aremania.

Aremania turun di Stasiun Gubeng Surabaya dengan kawalan ketat dari aparat kemanan sampai di Stadion Gelora 10 November (Tambak Sari). Di dalam Stadion Aremania aman karena tetap di kawal oleh aparat keamanan. Di tengah 20 ribu Bonek yang hadir Aremania bisa berjingkrak-jingkrak, menabuh drum dan meneriakkan yel-yel untuk mendukung Juan Rubio dan kawan-kawan (Jawa Pos 17 November 1997). Rencana awal Aremania pulang dari stadion 10 menit sebelum pertandingan berakhir, akan tetapi rencana itu berubah menjadi 15 menit sebelum pertandingan selesai. Saat keluar dari stadion seorang Aremania bernama El Kepet terkena lemparan batu. Sampai di stasiun Gubeng Aremania binggung mencari radio untuk mendengarkan kabar terbaru dari pertandingan Persebaya vs PS Arema, akhirnya menemukan radio milik penjaga toilet dan mendengarkan hasil akhir 0-0 secara spontan Aremania bernyanyi dan berjingkrak-jingkrak di peron stasiun Gubeng. Tour Aremania ke Surabaya ini menjadi yang terakhir karena setelah tahun 1997 Aremania di larang ke Surabaya karena alasan keamanan, begitu juga untuk pendukung dari Persebaya atau Bonek dilarang ke Malang. Peristiwa ini menunjukkan bahwa kelompok etnis atau kolompok komunitas identitas dapat bangkit kembali ketika kelompok

${ }^{11}$ Wawancara Heri Pandiono dengan Hendik koordinator tour Surabaya 1997. Wawancara oleh Heri Pandiono dilakukan di Malang pada tanggal 11 Agustus 2011.

${ }^{12}$ Aremanita adalah sebutan suporter Arema yang terdiri dari para wanita yang mendukung PS Arema. 
tersebut berada di bawah tekanan (Nyayu 2006: 87).

Liga Indonesia VI 1999-2000 merupakan tahun bersejarah bagi masyarakat Malang terutama Aremania karena pada akhir kompetisi mendapat gelar suporter terbaik seluruh Indonesia. Pada tahun 2000 prestasi PS Arema terbilang cukup bagus di tengah krisis finansial masih bisa lolos 8 besar di Gelora Bung Karno. Meskipun demikian perjalanan PS Arema dan Aremania penuh dengan perjuangan. PS Arema sebagai klub swasta mengadalkan pemasukan terbesar dari penjualan tiket masuk stadion. Pada putaran kedua saja kenaikan tiket 2 kali lipat dari putaran pertama 6-8 tiket ekonomi menjadi 1315 ribu, sedangkan VIP dari 15 ribu menjadi 30 ribu (Jawa Pos 6 April 2000). Harga tiket ini menjadi yang termahal untuk klub Indonesia, pada awalnya dengan menaikkan tiket maka akan menambah pendapat klub akan tetapi kebocoran tiket menjadi masalah. Permasalah tersebut adalah maraknya pemalsuan tiket pertandingan, akibat dari pemalsuan itu setiap pertandingan PS Arema selalu merugi 25 juta yang seharusnya pendapatan kotor 175 juta. Hal ini dapat dilihat dengan mudah yakni setiap bermain di stadion Gajayana selalu membludak hingga sintelban/batas lapangan dengan lintasan atletik. Manejer PS Arema Ir Gandhi Yogatama biasa dipanggil Abah Gandhi mengatakan:

"Saya bangga terhadap para Aremania yang
tidak mampu membeli tiket masuk tapi
kemauannya untuk menyaksikan dan
memberikan dukungan kepada PS Arema
dengan memanjat tembok Stadion, itu masih
mempunyai nilai perjuangan tersediri,
sedang pelaku pemalsuan ini tujuannya jelas
ingin mematikan PS Arema yang sedang
berjuang keras agar lolos ke Stadion Gelora
Bung Karno (Jawa Pos, 3 Mei 2000)."

Pemalsuan ini diketahui setelah adanya pengungkapan yang dilakukan oleh kepolisian Kota Malang setelah adanya laporan dari panitia pertandingan PS Arema vs Pusam Samarinda. Pertandingan terakhir PS Arema harus melawan Petrokima Gresik. Sejarah melawan tim Gresik tidak selalu manis, pada tahun 1992 trgedi Gresik yang melibat suporter Surabaya terjadi kerusuhan. Pada pertandingan terakhir liga Indonesia VI 2000 semuanya berbeda kali ini suporter asal Malang/Aremania disambut dengan hangat bahkan panitia pertandingan Petrokimia Gresik VS PS Arema Malang 6 juni 2000 memberikan diskon tiket pertandingan. Pemberian harga tiket khusus tersebut sebagai ucapan terimakasih lolos 8 besar PS Arema dan penghormatan terhadap Aremania. Selain itu pemberian sebagai harapan kepada PS Arema karena satu-satu wakil Jawa Timur yang lolos 8 Besar, sisi baik yang lain adalah mempererat silahturahim antar suporter kedua belah pihak (Jawa Pos, 31 Mei 2000)

Babak 8 besar Liga Indonesia dilaksanakan di Stadion Utama Bung Karno Jakarta. PS Arema berada di grup B bersama Persikota Tangerang, Persija Jakarta, dan Pelita Solo. Di babak 8 besar PS Arema kalah bersaing dengan Persikota Tanggerang dan Persija Jakarta. Pertandingan pertama melawan Persija Jakarta, PS Arema menang dengan skor 2-1, di pertandingan kedua PS Arema ditahan imbang 1-1 dengan Persikota Tangerang. Harapan PS Arema lolos ke semifinal untuk pertama kalinya pupus setelah kalah di pertandingan terkhir melawan Pelita solo dengan skor yang cukup telak 3-0. PS Arema hanya kalah selelisih gol dengan Persija Jakarta, PS Arema defisit 2 gol (3-5) sedangkan Persija imbang jumlah memasukan dan kemasukannya (4-4). PS Arema pada Liga Indonesia VI mendapat 33 kartu kuning dan 11 kartu merah, mengambarkan bahwa pada liga ini PS Arema terkenal dengan permainan kerasnya.

Meskipun tersingkir di babak 8 besar, PS Arema mempunyai prestasi tersendiri yaitu Aremania menjadi suporter terbaik untuk pertama kali di Indonesia. Penghargaan ini diberikan karena suporter yang berasal Jawa Timur sebelumnya terkenal sebagai perusuh dan selalu anarkis ketika tim kesayangannya kalah atau gagal lolos. Akan tetapi hal berbeda terjadi ketika babak 8 besar liga ke VI 1999-2000, Aremania dengan tertib dan damai keluar stadion dan pulang ke Malang setelah kesebelasannya kalah/ tersingkir. Hal itu yang membuat ketua PSSI saat itu Agum Gumelar terheran-heran dan kagum akan kedewasaan yang ditunjukkan oleh Aremania. Sebagai bentuk apresiasi PSSI memberikan 30 juta sebagai hadiah suporter terbaik nasional (Jawa Pos, 17 Agustus 2000). Sejak mendapatkan suporter terbaik nasional, identitas suporter PS Arema yang awalnya suka membuat keributan/kerusuhan berganti dengan suporter terbaik. 


\section{Penutup}

Pembentukan komunitas Aremania merupakan bagian dari kebutuhan akan identitas pemuda Malang. Secara geografis Kota Malang berada di pedalaman Jawa Timur, yang sering terpinggirkan baik secara budaya maupun sosial, sehingga kaum muda Malang membutuhkan identitas yang bisa menyetarakan mereka dengan kaum muda kota besar di Jawa Timur, dalam hal ini Surabaya. Sebagai contoh pemuda Malang selalu dianggap sebagai pemuda yang suka berbuat keributan dan Ndeso/kampungan. Selain itu pemuda Malang masih terpecah-pecah dalam kelompok/geng-geng antar kampung di Kota Malang. Kaum muda Malang menyadari perlunya akan identitas pemersatu di kalangan mereka. Pertama, dibentuk Arema Fans Club untuk mengkoordinir kaum muda Malang yang terpecah dalam kelompok/geng-geng untuk mendukung klub sepakbola asal Malang. Kedua, AFC cukup berhasil dalam menyatukan kaum muda karena menemukan musuh bersama yakni Persebaya Surabaya sebagai representasi pusat Jawa Timur, sehingga perlawanan dilakukan melalui kontruksi identitas kaum muda Malang dengan sepakbola sebagai medianya.

Konflik antara AFC dan pengurus Persema Malang setelah kericuhan pertandingan Persema Malang melawan Persebaya Surabaya pada tahun 1992, menyebabkan AFC menarik dukungan terhadap Persema Malang. Selanjutnya AFC memberikan dukungan kepada PS Arema Malang, dukungan yang dikoordinir AFC menjadi salah satu faktor PS Arema meraih juara Galatama. Pasca PS Arema meraih juara, pengurus AFC kehilangan koordinasi dengan kelompok-kelompok pemuda kota Malang karena kesibukan koordinatornya, akibatnya AFC bubar pada tahun 1993. Meskipun demikian pemuda Malang masih mendukung PS Arema dengan sebutan suporter Malang. Setelah melakukan koordinasi internal, pada tahun 1997 mereka sepakat untuk menggunakan nama Aremania sebagai nama pendukung PS Arema. Nama Aremania merupakan hasil kesepakatan bersama yang mengakibatkan perubahan adanya kesadaran kolektif untuk mengkontruksi identitas mereka dari perusuh menjadi suporter tertib dan kreatif.

\section{Daftar Pustaka}

Berger, P.L \& Luckmann, T. (1990). Tafsir Sosial atas Kenyataan: Risalah tentang Sosiologi Pengetahuan. Jakarta: LP3ES.
Buchari, Sri Astuti. (2010). Kebangkitan etnis menuju Politik Identitas. Jakarta: Yayasan Pustidaka Obor Indonesia.

Castells, Manuel. (2010). The Power of Identity. Oxford UK: Blackwell publising Ltd..

Iskandar, Dadan. "Identitas budaya dalam komunikasi antar-Budaya: Kasus Etnik Madura Dayak”, Jurnal Masyarakat dan Budaya Vol. VI No. 2/2004. Lembaga ilmu Pengetahuan Indonesia Pusat Penelitian Kemasyarakatan dan Kebudayaan.

Islafatun, Noor. (2014). Arek Bonek: Satu Hati Untuk Persebaya. Yogyakarta: Suka buku.

Kartodirdjo, Sartono. (1993). Pembangunan Bangsa. Yogyakarta: Aditya Media.

Kuntowijoyo. (2001). Pengantar Ilmu Sejarah. Yogyakarta: Yayasan Bentang Budaya

Kuper, S., Szymanski, S. \& Hardani, Wibi (Eds). (2010). Soccernomics. Jakarta: Airlangga.

Lukwira, Andreas L. (2009). Peran Kontrol Sosial Informal Di Aremania Dalam Mencegah Terjadinya Kerusuhan Suporter Sepakbola. Skripsi: Jurusan Kriminoliogi, Universitas Indonesia.

Mohamad, Hakim. (2016). Dinamika Komunitas Aremania: Suatu Bentuk Identitas Masyarakat Malang Tahun 1992-2010. (Universitas Diponegoro Semarang: Tesis Tidak Diterbitkan.

Mulyana, Slamet. (1979). Negarakretagama dan Tafsir Sejarahnya. Jakarta: Bhatara Karya Aksara.

Nyayu. (2006). Konflik Di Kalimantan: Arogansi Etnik Atau Identitas Etnik Yang Terusik. Jakarta: LIPI-CNRS.

Sutarto, Ayu. (2004). Pendekatan Kebudayaan Dalam Pembangunan Propinsi Jawa Timur. Jember: Kelompok Peduli Budaya \& Wisata Daerah Jawa Timur Kompyawisata.

Suryono, Soekanto. (1987). Sosiologi Suatu Pengantar. Jakarta: Rajawali Pers, 1987.

Wahyudi, H. (2009). The Land of Holigans (Kisah Para Perusuh Sepakbola). Jogjakarta: Garasi. 
Yovi Ardivitiyanto. (2014). Sejarah Perkembangan Musik Rock di Kota Malang Tahun 1970-an-2000-an: Kajian Eksistensi Sosial-Budaya. Skripsi, Jurusan Sejarah, Fakultas Ilmu Sosial.

\section{Surat Kabar}

Suara Karya. 8 Februari 1992

Merdeka, 15 februari 1992.

Merdeka 17 Mei 1994

Jawa Pos. 11 Agustus 2001

Jawa Pos 6 April 2000.

Jawa Pos, 3 Mei 2000.

Jawa Pos, 17 Agustus 2000 